\title{
Studying mathematics problem-solving classrooms. A comparison between the discourse of in-service teachers and student teachers
}

\author{
Javier Rosales \\ Josetxu Orrantia \\ Santiago Vicente \\ Jose M. Chamoso \\ University of Salamanca, Spain
}

\begin{abstract}
In the article we compare the approaches of 3 in-service teachers and 3 student teachers when they tried to solve a verbal arithmetic problem in the classroom. Each interaction was studied using a System of Analysis that takes into account the cognitive processes involved in the solution of a mathematic problem and describes the interaction at different levels showing what is done and to what degree teachers and/or pupils are responsible for what is done. The results of the study suggest that both groups of teachers are different in how they direct the student's attention toward the essential aspects implied in the resolution of word problem. On the one hand, the in-service teachers guaranteed students' understanding of the problem before dealing with the solution, while students teachers only did so when pupils committed errors. On the other hand, the in-service teachers allowed a high level of student participation, while student teachers took a more prominent role so children's participation was lower.
\end{abstract}

The importance of sociocultural context in the acquisition of mathematical knowledge is becoming more and more widely accepted. Specifically, educational research assumes that a large part of pupils' mathematics ideas are developed in the interaction between teachers and pupils in communication situations aimed at the acquisition of shared knowledge. In this regard, special attention has been paid to the study of the discourse used by teachers and pupils in classrooms with the object of analyzing aspects that aid the understanding of how maths learning takes place.

As we shall explain below, the study of educational practice in general and of discourse in particular has not been carried out in a uniform manner. Our aim in the present article is to

Acknowledgments: this research was supported by Grant SA127A06 to J. Rosales from the Junta de Castilla y León in Spain and by Grant BSO2003-05075 to J. Orrantia from the Ministerio de Educación y Ciencia in Spain. 
describe the verbal utterances of ordinary teachers in ordinary situations. We define ordinary teachers as those who deal with daily situations of word problem solving. That is, they are not expert in the domain of word problem solving, and their instructional practices are not intended to be examples of good educative innovation. In sum, our goal is to study standard practices regarding mathematical word problem solving because this way representative examples of the usual behaviour of teachers when solving word problems jointly with their students can be described. In particular, our interest lies in studying verbal utterances from the knowledge about the cognitive processes involved in solving a specific task. For this purpose we recorded, transcribed and analyzed the verbal utterances of 3 in-service teachers and 3 student teachers and their pupils as they tried to solve together a verbal arithmetic problem, taking into account the processes involved in the solution of a mathematics problem.

In a recent review, Hogan, Rabinowitz, and Craven (2003) explored the similarities and differences between expert and novice teachers in a discipline-specific context (i.e., by subject areas). These authors found that expert teachers perceive and recall more subtle classroom events and focus on individual pupil learning, and that they adjust instructional strategies accordingly. On the other hand, novice teachers tend to demonstrate few instructional strategies linked to the abilities of the class as a whole. These differences in abilities suggest that experts and novices perceive the classroom differently due to the formers' more elaborate schemata, profound knowledge of content and propensity for goal-oriented thinking.

\section{Theoretical perspective}

\section{Mathematics teaching classroom practices}

On studying mathematics teaching classroom practices, educational research pays particular attention to the instructional scaffolding provided in classrooms and the hierarchical status of the participants in the interaction. For example, Williams and Baxter (1996) identified two different types of instructional scaffolding: the scaffolding of mathematical ideas for pupils, or analytic scaffolding, and the scaffolding of norms for social behaviour and expectations regarding discourse, or social scaffolding. Hatano and Inagaki (1991) considered, in addition to instructional scaffolding, differences in the hierarchical status of teachers and pupils in classrooms. Specifically, they explained how the flow of information can occur vertically from a more knowledgeable other to a learner, or horizontally among peers at a similar level of expertise (Hatano \& Inagaki, 1991).

Despite an apparent uniformity in the study of educational practice, there are considerable differences in the way each aspect is studied. Thus, for example, differences can be identified in the representativeness of the teachers and tasks used in each case. In this regard, not all the educational practices studied are equally representative of what generally happens in classrooms; nor does there seem to be any guarantee, in every case, that the behaviour of the observed teachers is typical. For instance, works like those of Williams and Baxter (1996) or Nathan and Knuth (2003) analyze the behaviour of ordinary teachers, while in that of Inagaki, Hatano and Morita (1998) the teacher observed was one of the actual authors of the study. Likewise, as regards the representativeness of the tasks studied, the work by Williams and Baxter (1996) examined practices based on specific educational projects such as QUASAR; a similar case is that of the study by Inagaki, Hatano, and Morita (1998), who observed the implementation of an instruction programme protocolized by the researchers themselves, and therefore not comparable to what normally goes on in classrooms. On the other hand, Nathan and Knuth (2003) studied the teachers' instructional practice.

In our case, we set out to study ordinary teachers who teach in ordinary schools under ordinary conditions. The aim, therefore, was to describe the type of interaction ordinary teachers maintain with their pupils in the usual tasks of arithmetical problem-solving. In this type of study it is necessary to know what normally occurs in classrooms, if the researchers wish to make some 
kind of change in teachers' behaviour. Only by knowing what already happens will it be possible to formulate proposals for change which, on the one hand, are in line with customary practice, and on the other, can be relatively seamlessly integrated into everyday activities.

\section{The teacher's discourse in the mathematics classroom}

The language used in classrooms permits teachers and pupils to construct social and academic knowledge (Green \& Dixon, 1993). In the specific case of mathematics, the majority of the proposals formulated for analyzing educational practices consider the process of conceptualizing mathematics as a social endeavour taking place during the interaction between teacher and pupils. Accordingly, the nature of classroom discourse plays a critical role in the mathematics teaching classroom (Nathan \& Knuth, 2003). Likewise, Williams and Baxter (1996) pointed out that the discourse of teachers and pupils involves not only the establishment of social norms, but may also include the establishment of what counts as valid mathematical knowledge.

But the way of approaching the study of classroom discourse has not always been the same. Despite the fact that the objectives of each study determine the most appropriate unit of analysis, there is great variability in the way the discourse of teachers and pupils is broken down for its subsequent analysis. Thus, there are works in which the units of analysis are of a molar nature, as against others in which more elemental units of analysis are employed.

For example, if we consider the studies on whole-classroom mathematical discourse, we find that the units of analysis employed for coding pupils' utterances differ. Specifically, Inagaki, Hatano, and Morita (1998) broke down pupils' discourse into units of analysis of a molar nature, so that each utterance analyzed was defined as the total speech given by a single pupil until the experimenter teacher or another pupil took the floor (p. 508). However, Nathan and Knuth (2003) provided a more elemental description of utterance. For their analysis they used a coding scheme according to which each utterance was assigned a code labelling the content of the speech act. In this latter case, the unit of analysis (speech acts) is much more precise.

In the present study it was decided to use propositions as the minimum units of analysis (van Dijk \& Kintsch, 1978). Specifically, the verbal utterance of teachers and pupils was broken down into propositional units with the aim of making an exhaustive analysis of what occurred during the interaction. Likewise, we analyzed all the verbal utterances each teacher maintained with his pupils.

\section{Global theories versus specific theories}

Generally, research on the study of maths learning and teaching uses generic theoretical models for describing what happens in the classroom. For example, Cobb and Bauersfeld (1995) referred to the learning of mathematics as a collective enterprise in a sociocultural context. On many occasions these studies from a sociogenetic perspective take generic conceptions as the starting point for their analysis of what good learning and good teaching should be. In the work by Nathan and Knuth (2003), the coding scheme used for the study of whole-classroom mathematical discourse was not based on a specific model of classroom tasks; rather, it made use of an ad hoc model that permitted analysis of the flow of information and the nature of scaffolding. As the authors themselves suggested, the two elements of analysis made it possible to consider questions related to the type of information interchanged or the roles assumed by teacher and pupils during the interaction. However, these aspects were not described in relation to the solution of the specific task (on fractions, in this case) in which teacher and pupils are immersed.

There are also studies involving a somewhat more explicit description of what learning and teaching mean. For example, Meyer and Turner's (2002) analysis of instructional discourse for studying the process of scaffolding of pupil self-regulation was based on a precise theoretical model of what self-regulated learning involves. Thus, as the authors themselves indicate: To capture the majority of instructional interactions, we use a tiered coding scheme based on the theoretical definition of instructional scaffolding (p. 20). However, there are few works in which 
the study of what occurs in the classroom is based on our knowledge about the cognitive processes involved in the solution of specific tasks (Sánchez, Rosales, \& Cañedo, 1999).

The work presented here used a specific theoretical model on the solution of arithmetic problems that allows us to explain what teacher and pupils do based on the operations inherent to the solution of a problem, defined from cognitive analysis of human ability. In particular, we studied the interaction between teachers and pupils when they were trying to solve a problem belonging to the category of compare problems, according to the classification scheme introduced by Riley, Greeno, and Heller ${ }^{1}$ (1983) (see also Fuson, 1992; Kintsch, 1988, 1998; Reed, 1999; Verschaffel \& De Corte, 1997). This category involves a comparison between two sets, so that three sets are involved in the overall comparison: the compare set, which has to be compared to the reference set, and the difference between these two sets, the difference set. According to these models, when children attempt to solve this type of problem they need to understand linguistic terms, interpret the described situation, identify the appropriate operation, and compute an answer. Several computer simulation models were developed to explain this word-problem-solving process (Briars \& Larkin, 1984; Kintsch \& Greeno, 1985; Reusser, 1988; Riley et al., 1983).

The skilful solution process starts out from an initial analysis of the verbal formulation of the given problem, where children construct a network representation of the basic semantic relationships between the main quantities in the problem, in terms of the above-mentioned basic semantic structure. Thus, children have to understand the comparison of sets, that is, they must identify, within the context of the problem, the compare set (the set being compared to another), the reference set (this other set), and the difference set.

However, this knowledge is not sufficient for solving the problem. According to several models (e.g., Riley et al., 1983; Riley \& Greeno, 1988), the more difficult compare problems, with an unknown reference set, can only be solved by mapping the textual information given in the problem onto a part-whole schema, that is, the original problem representation in terms of a compare schema is re-represented in terms of a part-whole structure. Thus, when the sets involved in the quantitative comparison are represented in part-whole relations, the children know that "small set=large set-difference set" or "large set=small set+difference set" (Stern, 1993), and this allows them to infer from the relational statement whether the set mentioned in the assignment sentence is the small set or the large set, and on this basis, to decide on the appropriate operation (to add or subtract). Subsequently, with the help of this knowledge, the textual information can be directly transformed into a mathematical equation.

Another way to solve unknown reference set problems is not to represent them in partwhole relations, but to use a linguistic restructuring strategy (Lewis \& Mayer, 1987), which permits their transformation into easier unknown compare set problems.

Finally, several models pay more attention to the importance of children's understanding of the situational context described in the problem (Kintsch, 1988, 1998; Nathan, Kintsch, \& Young, 1992; Reusser, 1988; Staub \& Reusser, 1995). This situational context guides the understanding of specific story events, such us the actions, needs or intentions of the actors involved.

In sum, it is this knowledge about the cognitive processes involved in problem-solving that we used for interpreting what occurred in the interaction that took place between teachers and pupils.

\section{Method}

\section{Participants}

In this work we analyzed the verbal interactions of 3 in-service primary education teachers with more than 10 years' experience and 3 student teachers with their pupils (aged 8 to 10 years) while they were solving a verbal arithmetic problem. The number of students in each classroom varied from 17 to 20 , and the sessions were approximately 15-20 minutes 
long. The 3 in-service primary education teachers were selected from a group of teachers at a state (public) school in Salamanca (Spain) who were participating in a training programme focusing on the solution of maths problems. Among the activities of this programme was the recording of some of the normal classes given by the teachers. Specifically, these three teachers were selected at random from among those who volunteered for their classes to be recorded. As regards the 3 student teachers, they were randomly selected from among a group of student teachers on teaching practice in state (public) schools in the city of Salamanca (Spain).

\title{
Problem used in the study
}

The problem used was as follows:

\begin{abstract}
A wine producer wants to replace his wine vats because this year he has bought more grapes. The wine vats he currently has hold 158 litres, but these wooden vats hold 26 litres fewer than new metal ones would. Work out how many litres the new metal vats will hold.
\end{abstract}

In line with the problem-solving models presented in the first part of this work, the wineproducer problem involves a comparison between two sets. Its solution involves identifying the compare set, the reference set and the difference set. Thus, an assignment sentence specifies a numerical value for the compare set ("The wooden vats hold 158 litres of wine"). This sentence is followed by a relational statement that defines one set in terms of another ("These vats hold 26 litres fewer than the metal vats"), that is, the difference set. Finally, a question asks for the value of the unknown reference set ("How many litres do the new metal vats hold?").

However, as pointed out above, in order to solve this problem it is necessary to map the text information onto a part-whole schema. Thus, the solver has to infer from the relational statement that the compare set (the wooden vats) is the small set and the reference set (the metal vats) is the large set, and hence, can apply the operation $158+26$, because "large set=small set+difference set". Another way to do this is through the linguistic restructuring strategy (Lewis \& Mayer, 1987), whereby the relational statement of an unknown reference set problem such as "these wooden vats hold 26 litres fewer than the metal ones", could be transformed into "the metal vats hold 26 litres more than the wooden vats". In this way, the linguistic information used in the relational statement is matched to the situation, so that it can be transformed into a mathematical equation ("more than", therefore: add).

Finally, to understand the situational context, the solver must infer the needs of this wine producer and the intentions derived from them, which in turn determines the causal structure of the problem. This qualitative representation should include the notion that the wine producer had a lot of grapes, and that because of this he will produce more wine and need to buy new, bigger, metal vats.

Graphically, this can be shown in Figure 1.

\section{Analysis procedure}

Each one of the 6 teachers was audio-recorded while he solved an arithmetic problem with his pupils and the content of the recording was transcribed and analyzed. Solution of the problem took place in ordinary classrooms and during the time normally devoted to this type of work. The interaction by the in-service teachers was recorded before the start of the Training Programme mentioned above; the student teachers were recorded in one of their classroom interventions during the third week of their teaching practice.

For analyzing each interaction we used a variant of a System of Analysis already employed on previous occasions. Specifically, one version of this System was used for studying the interactions of teachers with their pupils when reading a text together (Rosales, Iturra, Sánchez, \& de Sixte, 2006; Sánchez, Rosales, \& Suárez, 1999;), one for analyzing the 
interaction between assessors and assessed (García, Rosales, \& Sánchez, 2003), and another for describing the form of the interaction between teachers and pupils during the solution of maths problems (Del Río, Sánchez, \& García, 2000).

The System of Analysis focuses specifically on verbal utterances and describes the interaction at two different levels. The first of these permits us to identify what teachers and pupils do during the interaction, while the second indicates the degree of participation from each side in carrying out the task. Below we describe each level.

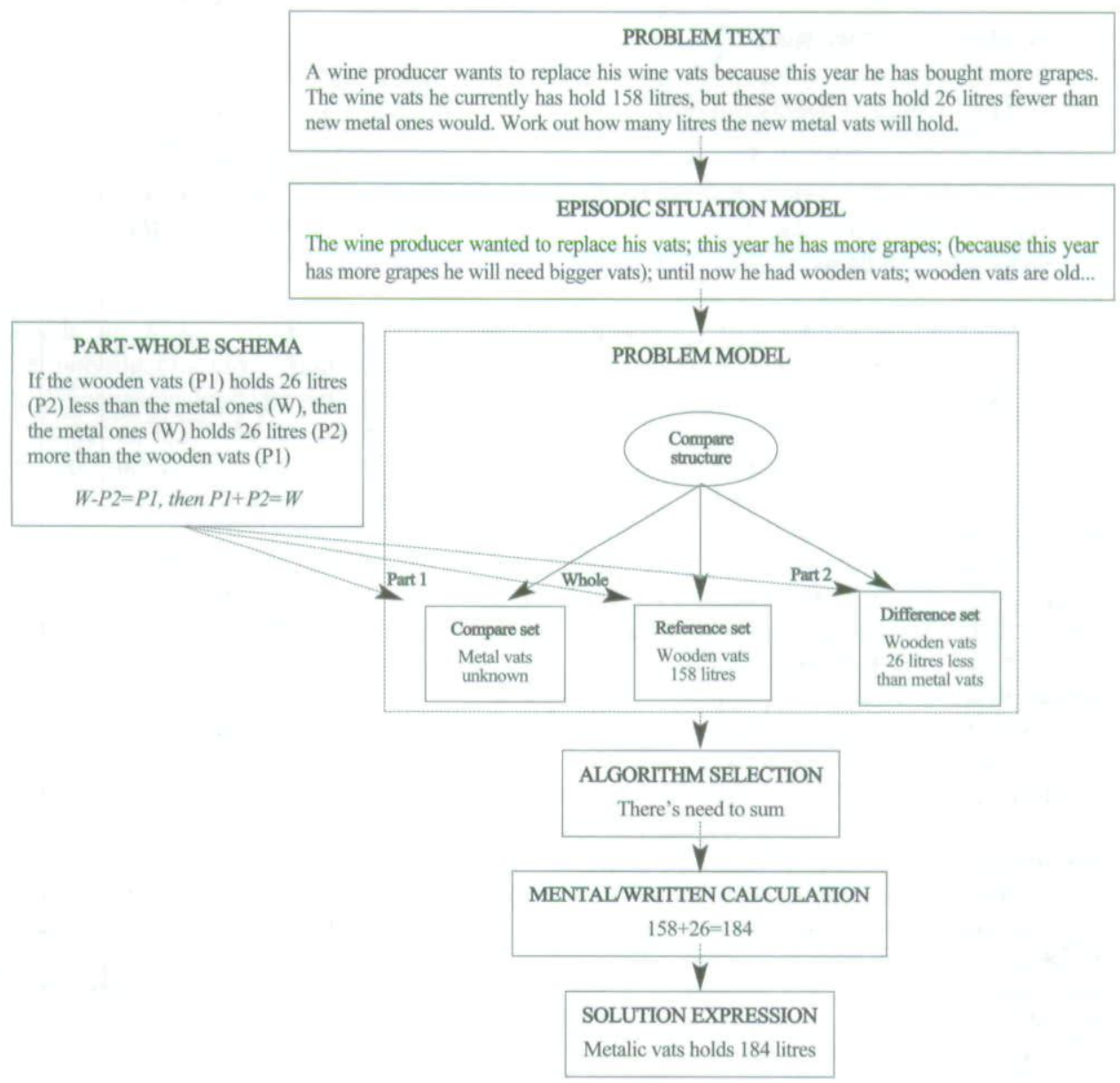

Figure 1. Cognitive processes involved in solving a compare problem

Note. $\mathrm{P} 1=$ Part $1 ; \mathrm{P} 2=\mathrm{Part} 2 ; \mathrm{W}=$ whole set. The general steps of the problem solving process, namely, construction of problem text, episodic situation model and problem model (applying part-whole knowledge when necessary) are common for solving problem of all types. However, each problem type has its own problem model, that is, for change problems the three sets involved would be an initial set, a change set and a final set, while for combine problems would be smaller part, the bigger part and the whole.

\section{What is done?}

The basic objective is to make explicit what teachers and their pupils did to solve the problem through the study of their verbal utterances. In this case, it involves making explicit what is made public in the classroom, and therefore what is the object of attention and analysis. For example, on solving a problem, teachers and their pupils may identify the meaning of 
some words, select the data presented or identify the operations necessary for its solution. In that case, it is relevant to identify the referents of the content that is made public so as to interpret them in terms of the processes involved in the problem-solving.

In order to identify the public content of the interaction, the System of Analysis determines first of all its global Episodes. An Episode is defined as a set of activities that presents:

- A recognizable objective or goal

- A regular structure of participation

- A recognizable sequence (of activities)

In the present work we distinguish two types of Episode. One Episode devoted to the understanding of the problem, and another devoted to its solution. In the former, all the actions of teacher and pupils were aimed at achieving an appropriate representation of the problem. In the latter, the activity was oriented to the application of the algorithm that would permit the solution of the problems. The following texts are examples for each one of these episodes:

\section{Example 1:}

Teacher: Right. Do we understand what the problem is about?

Pupil: Yes.

Teacher: Let's see... What did this wine-producer have? Ana, what did this wine-producer have?

Pupil: $\quad$ Uhm...

Teacher: What did he have?

Pupil: Vats of wine.

Teacher: Vats of...?

Pupil: Of wine.

Teacher: Yes, vats of wine, but, made of what?

Pupil: Of wood.

Teacher: Of wood. He had wooden vats. And he wants to change them for vats...

Pupil: $\quad$ Made of... Metal ones.

Teacher: For metal vats. The thing is that the wooden vats, ... How many litres do they hold?

Pupil: 158 litres.

Teacher: That's right. The wooden vats hold 158 litres; here we have a wooden vat (drawing it on the board), and this vat holds 158 litres. Ok?

Teacher: He's going to change them. And why is he going to change them?

Pupil: Foooor... metal vats.

Teacher: For metal vats; for vats made of metal. Well I don't know, but the problem does tell us whether they are smaller or bigger!; it tells us whether there are more... whether the wooden ones hold more litres or the metal ones hold more. I don't know which type holds more litres, there it tells us: I don't know which hold more or which hold less, but if I read the problem... I'll find out! Ok?

Teacher: Which hold more?

Pupil: The metal ones.

Pupil 1: The metal ones.

Teacher: The metal ones hold more. So if I know how many litres the wooden vats hold, and that the metal ones hold more, I can know how many the metal ones hold. 


\section{Example 2:}

Teacher: Froilán, What is it necessary to do?

Pupil: Multiplication.

Teacher: No. What are 158 litres?

Pupil: Uhm...

Teacher: The litres that are in...

Pupil: That are in... that... that are in metal vats.

Teacher: No! That means that you did not read the problem well. Read.

Pupil: "The wine vats he currently has hold 158 litres".

Teacher: Then what are these 158 litres?

Pupil: The litres than one metal vat holds.

Teacher: ... that one metal vat holds. Then... you should know how many litres are in one vat made of...?

Pupil: Wood.

Teacher: You already know how many litres a wooden vat holds! 158 litres!

Pupil: Yes.

Teacher: Then you should know how many litres a metal vat holds! And if one holds more or fewer litres?

Pupil: More.

Teacher: Ok. So let's see how many litres are in one, one metal vat.

Pupil: $\quad 158+26=184$ litres. That's what a metal vat holds.

Teacher: That's in one?

Pupil: Metallic vat.

Teacher: Metallic vat, Ok.

Having described both Episodes making up the interaction, we made a detailed analysis of the discourse used by teachers and pupils. To this end, we first considered all the conversational turns that took place in the course of the Episode and grouped them in Interaction Cycles. Each Interaction Cycle covered the participations of teachers and pupils with a specific thematic content. Secondly, for each Interaction Cycle we extracted the content that was made public, identifying all the propositions it contained. We then determined the type of activity involved in each case. This allowed us, for example, to ascertain whether the public content of the interaction was aimed at the identification of the part-whole structure, at the identification of the semantic structure of the problem, or at the construction of a situational context. In any case, the public content was interpreted on the basis of our theoretical knowledge about the cognitive processes involved in solving an arithmetic problem.

Tables 1 and 2 show examples of all that has been explained, together with the interjudge reliability obtained for each one of the analysis dimensions ${ }^{2}$. Table 1 was taken from a fragment of an Episode aimed at understanding of the problem in which, after reading it, the teacher begins the interaction. The first column shows the literal transcription of the interaction segmented in Interaction Cycles (separated by a double line spacing). The second column shows the sequence of conversational turns in each one of the Cycles. In this case, IRE structures of participation that occurred during the interaction were identified. An IRE structure of participation (Mehan, 1979) represents the simplest - and also one of the most usual - structures in the interaction. In this structure of participation the teacher begins the interaction and also provides children with an evaluation or feed-back about his or her answer. The third shows the content that was made public in each Interaction Cycle, and the fourth lists the activities referred to by the content that was made public. More concretely, the fourth 
column shows the activities developed by teachers and/or pupils in order to construct the public contents jointly during the interaction using the same terms as in Figure 1. We will explain this more precisely.

Table 1

Example of application of the system of analysis to an episode of understanding

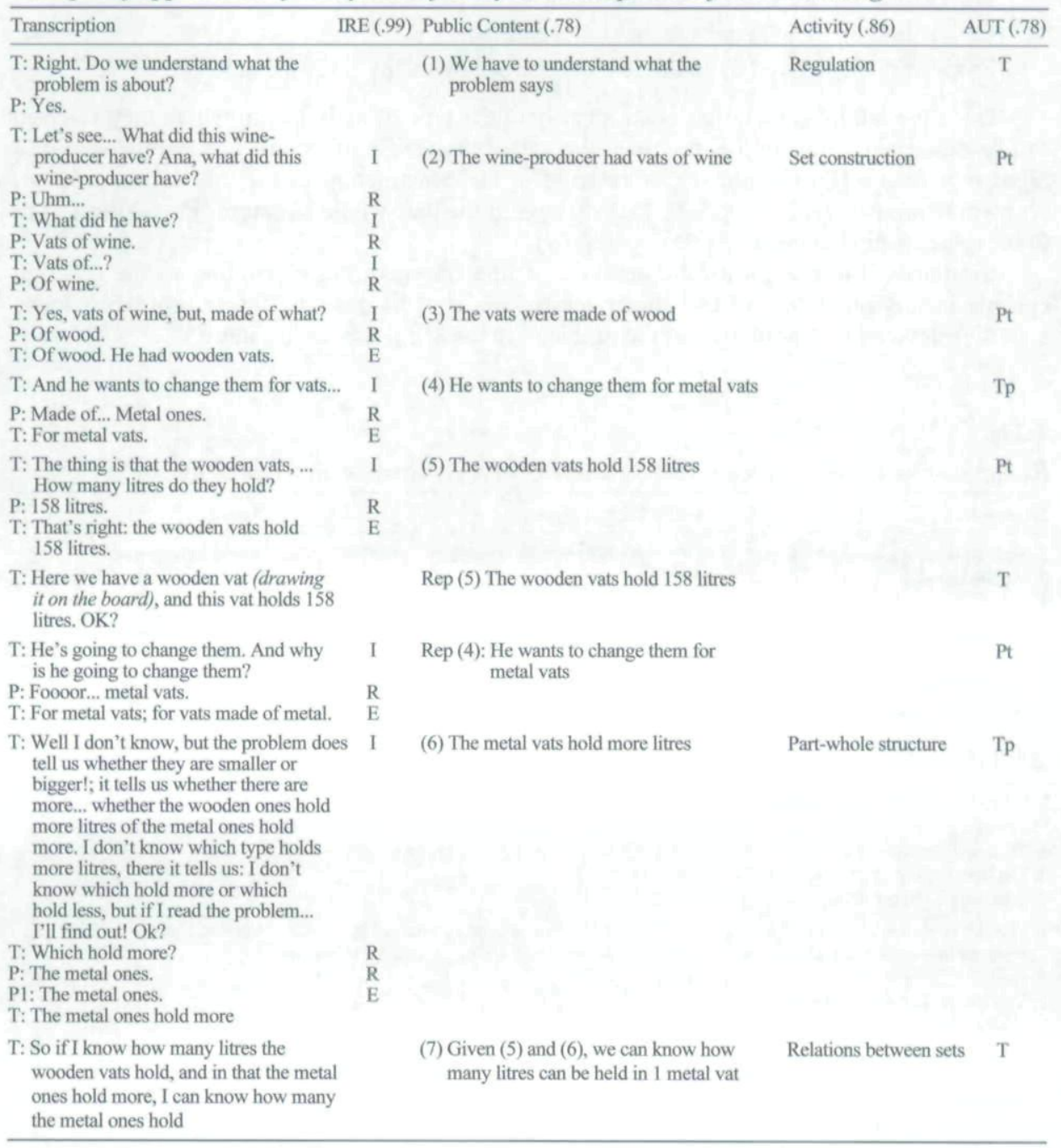

Note. I: inquiry, R: response, E: evaluation, P: Pupil autonomy, Pt: Shared autonomy pupil-teacher (open question), Tp: Shared autonomy teacher-pupil (closed question), T: Teacher autonomy.

Table 1 reveals how the interaction is divided in Cycles when there is a change in the thematic content to which teacher and pupils refer. For example, in the second Cycle, teacher and pupils speak of vats of wine, whilst in the third they introduce a new element: the fact that these vats were made of wood. Obviously, each of these Interaction Cycles is made up of a certain number of IRE exchanges.

The public content of the fragment considered is as follows: 
Proposition 1: We have to understand what the problem says.

Proposition 2: The wine producer had vats of wine.

Proposition 3: The wine vats were made of wood.

Proposition 4: He wants to change them for metal vats.

Proposition 5: The wooden vats hold 158 litres.

Proposition 6: Repetition of proposition 5.

Proposition 7: Repetition of proposition 4.

Proposition 8: The metal vats hold more litres.

Proposition 9: Given 5) and 8), we can know how many litres the metal vats hold.

Once the public content has been identified, the type of activities to which they referred can be described. Thus, in this fragment the verbal utterances of teacher and pupils were of a regulatory nature (Proposition 1), or referred to the construction of the sets involved in the problem (Propositions 2, 3, 4, 5, 6, 7), to access to the part-whole structure (Proposition 8) or to the relationship between sets (Proposition 9).

Similarly, Table 2 shows the analysis of one fragment corresponding to the solution episode in the interaction of one in-service teacher. In this case the fourth represents those activities devoted to the solution of the problem, in the same way as in Figure 1

Table 2

\section{Example of application of the system of analysis to an episode of understanding}

\begin{tabular}{|c|c|c|c|c|}
\hline Transcription & IRE & Public Content & Activity & AUT \\
\hline $\begin{array}{l}\text { T: Froilán, What is necessary to to do? } \\
\text { P: Multiplication } \\
\text { T: No. }\end{array}$ & $\begin{array}{l}\text { I } \\
\text { R } \\
\mathrm{E}\end{array}$ & A multiplication is necesary & Algorithm selection & Tp \\
\hline $\begin{array}{l}\text { T: What are } 158 \text { litres? } \\
\text { P: Uhm... } \\
\text { T: The litres that are in... } \\
\text { P: That are in... that... that are in metal vats } \\
\text { T: No! That means that you did not read } \\
\text { the problem well. } \\
\text { Read. } \\
\text { P: "The wine vats he currently has hold } \\
158 \text { litres" } \\
\text { T: Then what are these } 158 \text { litres? } \\
\text { P: The litres than one metal vat holds. } \\
\text { T: ...that one metal vat holds. }\end{array}$ & $\begin{array}{l}\mathrm{I} \\
\mathrm{R} \\
\mathrm{I} \\
\mathrm{R} \\
\mathrm{E} \\
\mathrm{I} \\
\mathrm{R} \\
\mathrm{I} \\
\mathrm{I} \\
\mathrm{R} \\
\mathrm{E}\end{array}$ & Wooden vats holds 158 litres & Set construction & Tp \\
\hline $\begin{array}{l}\text { T: Then... you should know how many } \\
\text { litres are in one vat made of...? } \\
\text { P: Wood. } \\
\text { T: You already know how many litres a } \\
\text { wooden vat holds! } 158 \text { litres! } \\
\text { P: Yes. } \\
\text { T: Then you should know how many litres } \\
\text { metal vat holds! }\end{array}$ & $\begin{array}{l}\text { I } \\
\text { R } \\
\mathrm{E}\end{array}$ & $\begin{array}{l}\text { We know that wooden vats holds } 158 \text { litres, } \\
\text { but we need to know the capacity of metal vats }\end{array}$ & Relations between sets & $\mathrm{T}$ \\
\hline $\begin{array}{l}\text { T: ¿And if one holds more or fewer litres? } \\
\text { P: More. } \\
\text { T: Ok. }\end{array}$ & $\begin{array}{l}\mathrm{I} \\
\mathrm{R} \\
\mathrm{E}\end{array}$ & Metal vats are bigger than wooden vats & Part-whole structure & $\mathrm{Tp}$ \\
\hline $\begin{array}{l}\text { T: Ok. So let's see how many litres are in } \\
\text { one, one metal vat. } \\
\text { P: } 158+26=184 \text { litres. }\end{array}$ & $\begin{array}{l}\mathrm{I} \\
\mathrm{R} \\
\mathrm{I}\end{array}$ & $158+26=184$ & Written calculation & $\mathrm{Tp}$ \\
\hline $\begin{array}{l}\text { P: (184 litres) That's what a metal vat holds. } \\
\text { T: That's in one..? } \\
\text { P: Metallic vat. } \\
\text { T: Metallic vat, OK }\end{array}$ & $\begin{array}{l}\mathrm{R} \\
\mathrm{I} \\
\mathrm{R} \\
\mathrm{E}\end{array}$ & Metal vats holds 184 litres & Solution Expression & $\mathrm{Pt}$ \\
\hline
\end{tabular}

Note. I: inquiry, R: response, E: evaluation, P: Pupil autonomy, Pt: Shared autonomy pupil-teacher (open question), Tp: Shared autonomy teacher-pupil (closed question), T: Teacher autonomy. 
In sum, this level of analysis permits identification of what is made public during the interaction, so that it can be interpreted in terms of what solving a problem involves.

\section{Who does it?}

The basic objective of this level of analysis was to clarify the participation of teachers and their pupils in the construction of the public content. In order to do so, the level of participation in the construction of the idea(s) in each interaction cycle was measured. In this sense, one idea can be formulated by the teacher, without any participation of the children, or on the contrary the children can generate the idea without any help from the teacher. In addition, the kind of questions formulated by the teachers was also studied, by analyzing whether they were open or closed questions. Open questions allowed children to reach a higher participation level, while closed questions, in which the number of possible answers is limited, decreased the participation level of the children.

Consequently, the level of participation of teachers and/or pupils was measured by analyzing the situations in which the teacher or the pupil generated the idea and also the kind of questions formulated. This way, the participation of teachers and pupils is described using the following Scale:

- The construction of ideas is assumed by the teacher (T). The teacher states the complete idea.

- The construction of ideas is assumed by the pupil (P). The pupil states the complete idea

- The teacher and pupil share responsibility for idea construction, though with a higher participation of the teacher (Tp) Statement of the ideas is shared between teacher and pupils. In this case the teacher initiates the exchange with a closed question that includes a part of the content of the proposition that is made public.

- The teacher and pupil share responsibility for idea construction, though with a higher participation of the pupil (Pt). Statement of the proposition is shared between teacher and pupils. In this case the teacher initiates the exchange with an open question that concludes with a positive evaluation of the response given by the pupil.

Once more, Table 1 allows us to clarify the explanation. As can be seen, Proposition 1: We have to understand what the problem says, was formulated by the teacher, and therefore it was him that assumed responsibility for it. Thus, it is rated as Teacher autonomy (T). The same applies to Propositions 6 and 9. As regards Proposition 4: He wants to change them for metal vats, it is categorized as (Tp) since the teacher formulated a closed question that included part of the propositional content that is made public; Proposition 8 was also categorized in the same way. The rest of the propositions were classified as $(\mathrm{Pt})$, since the teacher asked his pupils open questions. For example, Proposition 2: The wine producer had vats of wine emerged from the teacher's open question: What did this wine producer have?

In sum, this Scale allows identification of the degree of responsibility assumed by the teacher and his pupils in the construction of the public content.

\section{Measures}

\section{Measures for evaluating what is done}

First of all, in order to clarify the relationship between the content that was made public and the processes involved in the problem-solving, we identified the referent of each item of content made public during the interaction. Specifically, we considered the mean of cycles devoted by each group of teachers to each of the activities involved in solving the problem.

Secondly, in order to identify the differences in the way the two groups of teachers behaved, we calculated the percentage of Interaction Cycles each group devoted to the 
Understanding Episode and the Solution Episode. Furthermore, for each Episode, we noted the percentage of Cycles devoted to each isolated activity in the System of Analysis.

\section{Measures for evaluating who does it}

In order to evaluate the responsibility of teacher and pupils in the construction of public content we considered the responsibility of teachers and pupils in the development of each activity following the scale described below.

\section{Results and discussion}

Results will be presented following the above levels of what is done and who does it.

\section{What is done?}

From the results obtained in this study it can be stated that both groups of teachers made public the content necessary for solving the problem. Specifically, they made public the compare structure of the problem, identifying the reference set, the compare set and the difference set. Likewise, the in-service teachers and the student teachers made public the partwhole schema and mentioned the Episodic Situation Model.

Figure 2 clarifies this by showing the mean of cycles devoted by each group of teachers to each one of the activities involved in the solution of the problem. The figure distinguishes between understanding and solving activities.

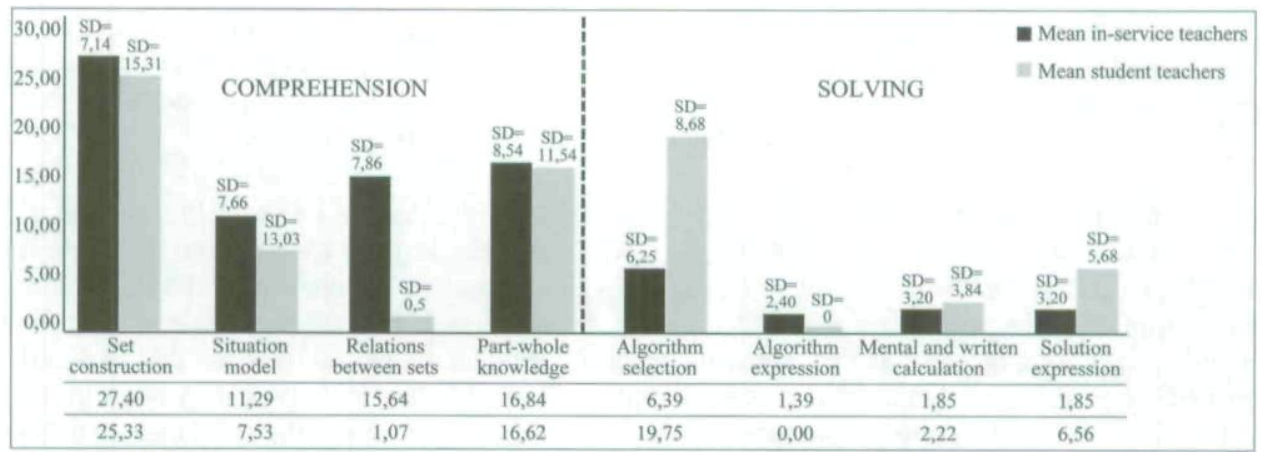

Figure 2. Mean of cycles devoted to each activity by in-service and student teachers

The fact that the two groups of teachers show some similarity in the content they made public makes sense, given that, as explained on referring to the problem-solving models, in order to guarantee solution of a problem it is essential to make explicit the compare structure of the problem and identify the part-whole structure. That is, in the first case: The wooden vats hold 158 litres of wine (the compare set), These vats hold 26 litres fewer than the metal vats (the reference set) and How many litres do the metal vats hold? (the compare set), and in the second: if the wooden vats hold fewer litres, the metal ones hold more litres.

However, there are some differences between the behaviour of both groups of teachers in each one of the episodes. In the episode of understanding, clear differences were found in the percentage of cycles devoted to the identification of relations between sets and also to the generation of the Situation Model of the problem. More concretely, the results support the idea that in-service teachers constructed sets but also the relations that can be established between them: 
Teacher: So if I know how many litres the wooden vats hold and that the metal ones hold more, I can know how many the metal ones hold

This example shows how the teacher explicitly says that there is a relation between the wooden and the metal vats and that considering both data it's possible to know which vat holds more litres.

Furthermore, in-service teachers try to reproduce, jointly with the pupils, the situational context in which the problem is embedded, although in this case the difference between expert teachers and student teachers is not so clear. An example of this is the following:

Teacher: Look: this wine producer is a man who has a loooooot, a lot of grapevines, so he has a huge vineyard! And he wants to renew his wine vats because this year he has more grapes than usual.

This is an example of how the teacher tries to establish a causal chain for the events of the problems that afterwards can be used to establish causal links between the sets and also between the quantities. Following Reusser (1988), the Episodic Situation Model represents the intentional, temporal and causal structure of the situation described by the problem text, and only when this mental model has been well-established can the mathematical relations between sets be inferred.

In the Solving Episode, student teachers devoted more interaction cycles to the selection the algorithm and to the expression of the solution:

Teacher: If the wooden vats hold 158 litres and they hold 26 litres fewer than the metal vats, how many litres do the metal vats hold?

Pupil: Uhmm...

Teacher: They will hold more, won't they? No?, No?

Pupil: Uhmm...

Teacher: How many more?

Pupil: $\quad$...

Teacher: Ok, so what you have to do?

Pupil: $\quad$... Umh, ... To divide?

Teacher: Why divide? Let's see, if the wooden vats hold $158 \ldots$

Pupil: $\quad$ To multiply.

Teacher: Wait, wait; the wooden vats hold 26 litres less than the metal vats, and the metal vats hold 26 litres more than the wooden vats, right?

Pupil: $\quad$...

Teacher: If wooden vats hold 26 litres less than the metal vats, obviously the metal vats holds 26 litres more than the wooden vats, don't they?

Pupil: Yes

Teacher: If the wooden vats hold 158, how many litres do the metal vats hold?

Pupil:

Teacher: What do you have to do to find out?

Pupil:

In this example we can see how the teacher asks children to look for the algorithm that must be applied to solve the problem, even when the pupil seems not to understand the reasoning provided by the teacher. That is, the worry of the teacher is mainly to make the right selection of the algorithm.

The same can be said about the expression of the solution. The student teachers devoted a bigger proportion of interaction cycles to express correctly the result of the algorithm. 
Teacher: And what are these?

\section{Pupil: Eh... The litres that one metal vat holds!}

Teacher: The litres that one metal vat holds, one metal vat!

In sum, based on these results for the group of teachers analyzed, we can conclude that the in-service teachers spent a bigger proportion of interaction cycles guaranteeing the children's understanding of the problem, while student teachers were more worried about solution procedures.

In the same vein, a detailed analysis of the way in which these activities were distributed in the Understanding and Solution Episodes reveals clear differences. We shall now present the percentage of Interaction Cycles devoted to each Episode.

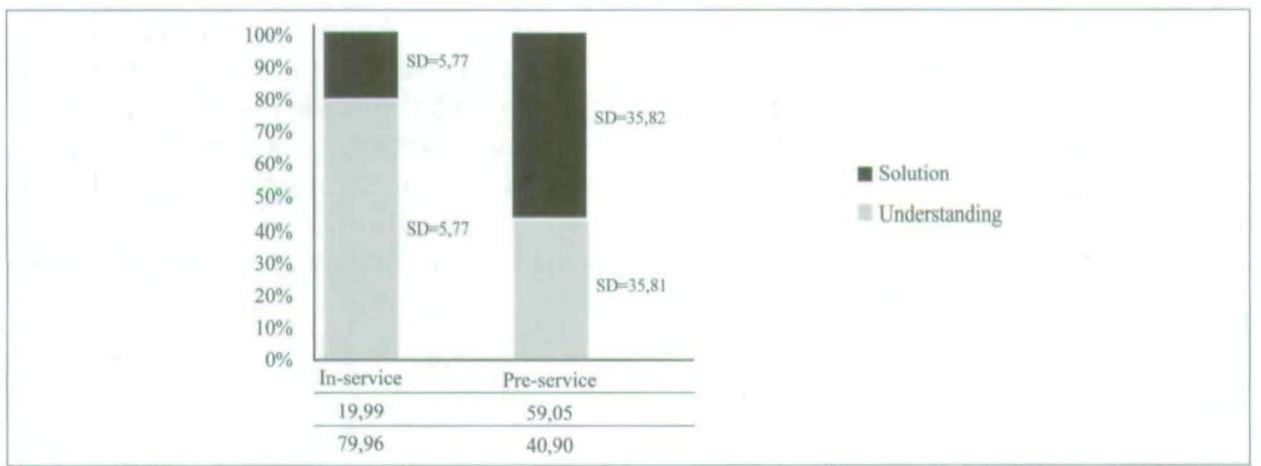

Figure 3. Mean percentage of cycles devoted to understanding and solution activities inservice and student teachers.

Figure 3 shows how the in-service teachers devoted a larger number of Interaction Cycles to the Understanding Episode. That is, the majority of contact time with pupils was devoted to creating a coherent representation of the problem, while the time devoted to solving the algorithm was much less. In contrast, in the case of the student teachers the majority of the Interaction Cycles were devoted to the Solution Episode, so that the majority of the exchanges they maintained with their pupils focused on solving the algorithm.

Similarly, if we consider the activities directly related to understanding the problem, we can see that the in-service teachers developed them in the Understanding Episode, while the student teachers did so in the Solution Episode. The in-service teachers differed from the student teachers in that they guaranteed the review of all the content of the problem (set construction), showed the global relationships between the ideas of the problem (relations between sets) and clarified the part-whole structure. On the other hand, the student teachers situated the majority of the activities related to understanding of the problem in the Solution Episode. This may be due to the fact that their pupils committed more errors in selection of the operation and in expression of the result, obliging them to readdress the understanding of the problem statement. So we can see that, in the Solution Episode, the student teachers devoted a larger number of cycles to the selection algorithm than the in-service teachers.

Summarizing, on the basis of these results it can be stated that the in-service teachers created a shared understanding with their pupils about the basic meaning of the problem before making a decision about the operation to be carried out. In contrast, the student teachers only considered this question when they tried to select the most appropriate operation for solving the problem. Thus, the strategic behaviour of the in-service teachers compared to the student teachers consisted in guaranteeing a shared understanding of the problem before deciding on the sign of the operation to be used. 


\section{Who does it?}

Figure 4 shows the responsibility assumed by teachers and pupils in each group with respect to the activities carried out during the interaction. Specifically, it shows the mean of the activities carried out by teachers and by pupils in accordance with the scale presented above. First of all we present the results related to the Understanding Episode, followed by those for the Solution Episode.

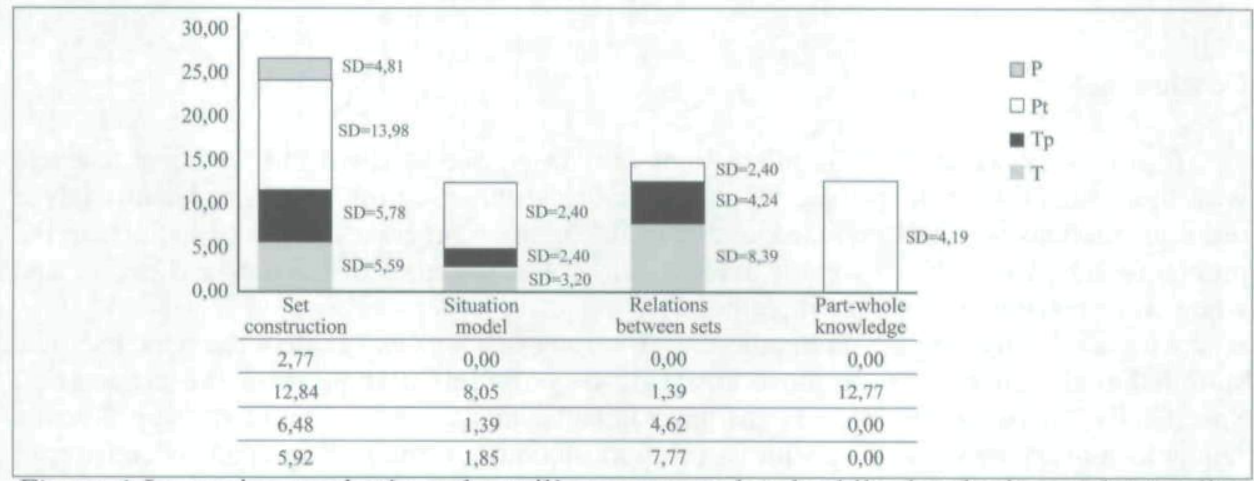

Figure 4. In-service teacher's and pupil's autonomy level while developing understanding activities in comprehension episode. P: Pupil autonomy, Pt: Shared autonomy pupilteacher (open question), Tp: Shared autonomy teacher-pupil (closed question), T: Teacher autonomy.

Figure 4 shows how the pupils took on greater responsibility in the cases in which they interacted with in-service teachers. Specifically, the teachers assumed greater control in the identification of the relationships between sets, leaving their pupils more responsibility in the set construction, in the creation of the part-whole structure and in the creation of a situational model.

For their part, as can be seen in Figure 5, the pupils who interacted with the student teachers scarcely participated in the representation of the problem, since, in all the activities, responsibility for the task fell on the teacher.

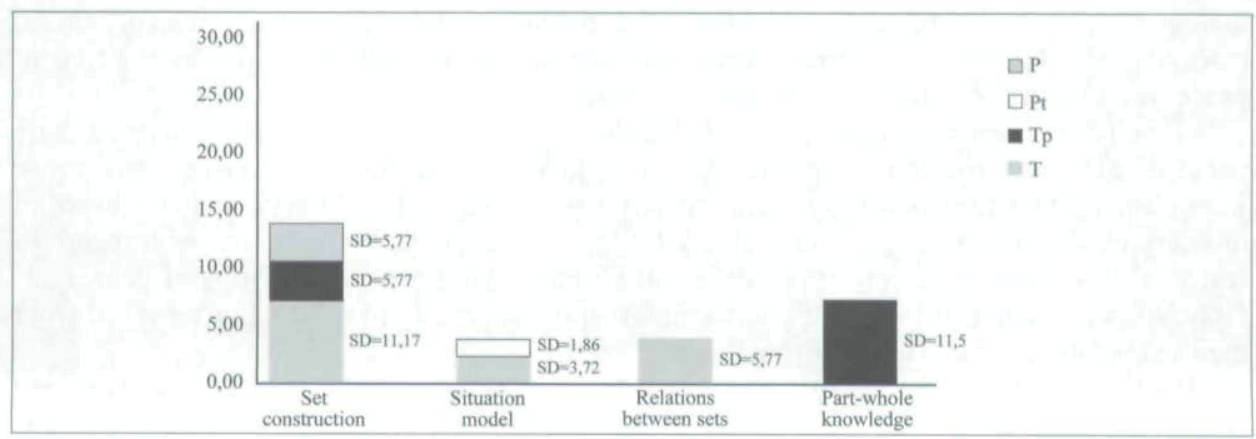

Figure 5. Student teacher's and pupil's autonomy level while developing understanding activities in comprehension episode. P: Pupil autonomy, Pt: Shared autonomy pupilteacher (open question), Tp: Shared autonomy teacher-pupil (closed question), $\mathrm{T}$ : Teacher autonomy 
In sum, these results suggest that the in-service teachers gave their pupils more opportunity to participate throughout the problem-solving process. Indeed, the responsibility assumed by the pupils of the in-service teachers was greater than that of the pupils who worked with the student teachers. In the former case, the content that was made public was at certain times the responsibility of the pupils. In the latter case, on the other hand, it was the teachers that assumed greater responsibility, either because they actually took on the task of making public the content related to each activity, or because this content emerged from closed questions that limited the pupils' participation.

\section{Conclusion}

In this work we studied the interactions of 3 in-service teachers and 3 student teachers with their pupils when they were solving a verbal arithmetic problem. In order to analyze these interactions we used knowledge about the cognitive processes involved in solving the problem. Thus, we analyzed what is made public in the discourse of teachers and pupils, and who was responsible for making it public.

After analyzing the verbal utterances of in-service teachers and student teachers, it can be stated that the former made more strategic use of their discourse in the classroom. Specifically, the in-service teachers guaranteed their pupils an understanding of the problem's semantic content before dealing with its solution. In contrast, the student teachers considered the understanding of the problem basically when the pupils made errors in selecting the operation. Thus, and as Hogan, Rabinowitz, and Craven (2003) point out, the in-service teachers were more consistent and efficient, on using strategies adapted to the difficulty of the task. In our case, the strategic nature of the aids is interpreted through consideration of the cognitive demands of the task. That is, knowledge about the operations inherent to the solution of a problem has made the teacher's task intelligible. That is, knowledge of the cognitive processes involved in the understanding and solution of a mathematical problem allows us to re-interpret the practices of teachers in terms of which of these processes are being promoted by one concrete interaction. In this sense, we could assume that not all activities developed by a teacher have the same value for solving a problem.

Likewise, with regard to the responsibility assumed by teachers and pupils in carrying out the task, it was shown that the in-service teachers allowed their pupils greater autonomy. These data concur with those of Blanton, Berenson, and Norwood (2001), for whom the discourse of novice teachers has a more univocal than dialogic nature. In the present study, the in-service teachers behaved in a strategic way, permitting their pupils to participate more in those tasks that were relevant to solving the problem. In this sense, what is truly important is not whether teachers are more or less dialogic with their pupils, but rather whether the dialogue established between them addresses essential elements of the task - which, indeed, can only be confirmed if one has access to specific models indicating the most relevant processes involved in a discipline-specific context.

Finally, detailed description of the behaviour of both groups of teachers provided quite precise information about how each group approached the task. Moreover, and more importantly, it in turn permits a detailed description of what ordinary teachers do in an ordinary classroom working on an ordinary task. Any changes to be suggested with regard to teachers' discursive behaviour involve first of all identifying their usual forms of behaviour. Only in this way it will be feasible to formulate proposals that are not too far removed from their everyday activity in the classroom.

Obviously, these conclusions must take into account our study's two slight failings, one related to the sample and the other related to the task to be performed. First, only six teachers were analyzed, so future research should increase the sample in order to support our findings more convincingly. Second, as we have only analyzed the understanding and solution processes of a single kind of mathematical problem (i.e., compare problems), the results obtained should be interpreted with proper academic caution. 
As we have already described at the beginning of this paper, limiting our study to only one kind of problem was a planned decision. Compare problems are the most difficult for children to solve, and because of this, we knew that not only would the understanding and solution process generate a lot of difficulties for both teachers and pupils to face, but we also knew that these problems would make our analysis of the interaction more interesting. However, the process by which different kinds of mathematical problems (e.g., change and combine) are solved should also be analyzed by further research.

\section{Notes}

1 The authors distinguished three basic categories of addition and subtraction word problems: Change, Combine and Compare. Change problems refer to dynamic situations in which some event changes the value of an initial quantity. Combine problems refer to static situations involving two quantities that are considered in combination. Compare problems involve two amounts that are compared and the difference between them. Within each of these three major semantic categories, further distinctions were made, resulting in 14 different types of addition and subtraction word problems.

2 In order to evaluate the reliability of the System of Analysis five fragments belonging to both of the episodes of the interaction - understanding and solution - were randomly selected. Four judges were independently asked to analyze these fragments by applying all steps of the System of Analysis. They were provided with an internal-use document in which this System was clearly described. The degree of reliability was obtained by dividing the total number of agreements by the total numbers of decisions to be taken.

\section{References}

Blanton, M.L., Berenson, S.B., \& Norwood, K. (2001). Using classroom discourse to understand a prospective mathematics teacher's developing practice. Teaching and Teacher Education, 17, 227-242.

Briars, D.J., \& Larkin, J.H. (1984). An integrated model of skill in solving elementary word problems. Cognition and Instruction, 1, 245-296.

Cobb, P., \& Bauersfeld, H. (1995). The emergence of mathematical meaning: Interaction in classroom cultures. Hillsdale, NJ: Lawrence Erlbaum.

Del Río, I., Sánchez, E., \& García, R. (2000). Análisis de la interacción maestro-alumnos durante la resolución de problemas aritméticos. Cultura \& Educación, 17/18, 41-61.

Fuson, K.C. (1992). Research on whole number addition and subtraction. In D. Grouws (Ed.), Handbook of research on mathematics teaching and learning (pp. 243-275). New York: Macmillan.

García, R., Rosales, J., \& Sánchez, E. (2003). El asesoramiento psicoedagógico como construcción de significados compartidos. Un estudio sobre su dificultad. Cultura \& Educación, 15(2), 129-148.

Green, J., \& Dixon, C. (1993). Introduction to special issue. Talking knowledge into being: Discursive and social practices in classrooms. Linguistics and Education, 5(3-4), 231-239.

Hatano, G., \& Inagaki, K. (1991). Sharing cognition through collective comprehension activity. In L. Resnick, J. Levine, \& S. Teasley (Eds.), Perspectives on socially-shared cognition (pp. 331-348). Washington, DC: American Psychological Association.

Hogan, T., Rabinowitz, M., \& Craven, J.A. (2003). Representation in teaching: Inferences from research of expert and novice teachers. Educational Psychologist, 38(4), 235-247.

Inagaki, K., Hatano, G., \& Morita, E. (1998). Construction of mathematical knowledge through whole-class discussion. Learning and Instruction, 8, 503-526.

Kintsch, W. (1988). The role of knowledge in discourse comprehension: A Construction-Integration model. Psychological Review, 95(2), 163-182.

Kintsch, W. (1998). Comprehension: A paradigm for cognition. Cambridge: Cambridge University Press.

Kintsch, W., \& Greeno, J. (1985). Understanding and solving word arithmetic problems. Psychological Review, 92, 109-129. 
Lewis, A.B., \& Mayer, R.E. (1987). Students's miscomprehension of relational statements in arithmetic word problems. Journal of Educational Psychology, 79(4), 363-371.

Mehan, H. (1979). Learning lessons: Social organization in the classroom. Cambridge, MA, Harvard University Press.

Meyer, D.K., \& Turner, J.C. (2002). Using instructional discourse analysis to study the scaffolding of student selfregulation. Educational Psychologist, 37(1), 17-25.

Nathan, M.J., \& Knuth, E.J. (2003). A study of whole classroom mathematical discourse and teacher change. Cognition and Instruction, 21(2), 175-207.

Nathan, M.J., Kintsch, W., \& Young, E. (1992). A theory of algebra-word problem comprehension and its implications for the design of Learning Environments. Cognition and Instruction, 9(4), 329-389.

Reed, S.K. (1999). Word Problems: Research and curriculum reform. Mahwah, NJ: Lawrence Erlbaum Associates.

Reusser, K. (1988). Problem solving beyond the logic of things: contextual effects on understanding and solving word problems. Instructional Science, 17, 309-338.

Riley, M.S., \& Greeno, J.G. (1988). Developmental analysis of understanding language about quantities of solving problems. Cognition \& Instruction, 5(1), 49-101.

Riley, N.S., Greeno, J., \& Heller, J.I. (1983). Development of children's problem solving ability in arithmetic. In H.P. Ginsburg (Ed.), The development of mathematical thinking (pp. 153-196). New York: Academic Press.

Rosales, J., Iturra, C., Sánchez, E., \& de Sixte, R. (2006). El análisis de la práctica educativa. Un análisis de la interacción profesor-alumnos a partir de dos sistemas de análisis diferentes. Infancia y Aprendizaje, 29(1), 65-90.

Sánchez, E., Rosales, J., \& Cañedo, I. (1999). Understanding and communication in expositive discourse: An analysis of the strategies used by expert and pre-service teachers. Teaching and Teacher Education, 15, 37-58.

Sánchez, E., Rosales, J., \& Suárez, S. (1999). Interacción profesor-alumnos y comprensión de textos. Qué se hace y qué se puede hacer. Cultura \& Educación, 14/15, 71-89.

Staub, F.C., \& Reusser, K. (1995). The role of presentational structures in understanding and solving mathematical word problems. In C.A. Weaver III, S. Mannes, \& C.R. Fletcher (Eds.), Discourse Comprehension: Essays in honour of Walter Kintsch (pp. 285-305). Hillsdale, NJ: Lawrence Erlbaum.

Stern, E. (1993). What makes certain arithmetic word problems involving the comparison of sets so difficult for children? Journal of Educational Psychology, 85, 7-23.

Van Dijk, W., \& Kintsch, T.A. (1978). Toward a model of text comprehension and production. Psychological Review, $85,363-394$

Verschaffel, L., \& De Corte, E. (1997). Teaching realistic mathematical modeling in the elementary school: a teaching experiment with fifth graders. Journal for Research in Mathematic Education, 28(5), 577-601.

Williams, S.R., \& Baxter, J.A. (1996). Dilemmas of discourse-oriented teaching in one Middle School Mathematics Classroom. The Elementary School Journal, 97(1), 21-38.

L'interaction de 3 professeurs expérimentés et de 3 professeurs débutants lors de la résolution d'un problème arithmétique verbal avec leurs étudiants dans la classe est analysée dans cet article. Chaque interaction a été étudiée au moyen d'un système d'analyse qui tient compte des processus cognitifs impliqués dans la résolution de problèmes mathématiques et qui décrit l'interaction à différents niveaux, démontrant ce qui est fait et la mesure dans laquelle les professeurs et les étudiants sont responsables de ce qui est fait. Les résultats de l'étude suggèrent que les deux groupes de professeurs sont différents quant à la manière dont ils attirent l'attention des élèves sur les aspects essentiels impliqués dans la résolution du problème. Tout d'abord, tandis que les professeurs expérimentés se sont assurés de la compréhension du problème par les étudiants avant de chercher la solution, les professeurs débutants ne l'ont fait que lorsque des erreurs 
ont été commis par les étudiants. En deuxième lieu, tandis que les professeurs expérimentés ont admis un plus fort degré de participation des étudiants, les professeurs débutants ont adopté un rôle plus prédominant permettant un moindre niveau de participation des élèves.

Key words: Classroom interaction, Expert and novice teachers, Word problem solving.

Received: February 2007

Revision received: August 2007

Javier Rosales. Department of Developmental and Educational Psychology. University of Salamanca, Faculty of Education, Pso. Canalejas 169,37008 Salamanca, Spain. E-mail: rosales@usal.es; Web site: www.usal.es/aiape

Current theme of research:

Analysis of discourse in classroom interaction; Text comprehension; Mathematical word problem solving.

Most relevant publications in the field of Psychology of Education:

Rosales, J., Iturra, C., Sánchez, E., \& de Sixte, R. (2006). El análisis de la práctica educativa. Un análisis de la interacción profesor-alumnos a partir de dos sistemas de análisis diferentes. Infancia y Aprendizaje, 29(1), 65-90.

Sánchez, E., Rosales, J., \& Cañedo, I. (1999). Understanding and communication in expositive discourse: An analysis of the strategies used by expert and pre-service teachers. Teaching and Teacher Education, 15, 37-58.

Josetxu Orrantia. Department of Developmental and Educational Psychology, University of Salamanca, Faculty of Education, Pso. Canalejas 169, 37008 Salamanca, Spain. E-mail: orrantia@usal.es; Web site: www.usal.es/aiape

Current theme of research:

Mathematical word problem solving; learning disabilities; cognitive processes involved in word problem solving.

Most relevant publications in the field of Psychology of Education:

Orrantia, J. (2003), El rol del conocimiento conceptual en la resolución de problemas aritméticos con estructura aditiva. Infancia y Aprendizaje, 26(4), 451-468.

Vicente, S., Orrantia, J., \& Verschaffel, L. (2007). Influence of situational and conceptual rewording on word problem solving. British Journal of Educational Psychology, 77(4), 829-840.

Santiago Vicente. Department of Developmental and Educational Psychology. University of Salamanca, Faculty of Education, Pso. Canalejas 169, 37008 Salamanca, Spain. E-mail: sanvicente@usal.es; Web site: www.usal.es/aiape

Current theme of research:

Mathematical word problem solving; learning disabilities; analysis of educational practices. 
Most relevant publications in the field of Psychology of Education:

Vicente, S., Orrantia, J., \& Verschaffel, L. (2007). Influence of situational and conceptual rewording on word problem solving. British Journal of Educational Psychology, 77(4), 829-840.

Vicente, S., Orrantia, J., \& Verschaffel, L. (in press). Influence of situational and mathematical information on situationally difficult word problems. Studia Psychologica.

Jose M. Chamoso. Department of Didactics of Mathematical and Experimental Sciences. University of Salamanca, Faculty of Education, Pso. Canalejas 169, 37008 Salamanca, Spain. E-mail: jchamoso@usal.es

Current theme of research:

Mathematical word problem solving; mathematics in the usual context; technology in Mathematics Education.

Most relevant publications in the field of Psychology of Education:

Chamoso, J.M. (2003). Considering dialogue as a social instrument in the Mathematics class. For the Learning of Mathematics, 23(1), 30-40. 
Copyright of European Journal of Psychology of Education - EJPE is the property of Instituto Superior de Psicologia Aplicada and its content may not be copied or emailed to multiple sites or posted to a listserv without the copyright holder's express written permission. However, users may print, download, or email articles for individual use. 